- transforming physician practices to enable them to adapt and excel in today's changing health care environment

- achieving payment reform that facilitates and accelerates the shift away from volume-based care and toward value-based care

- pursuing workforce education and development goals that aim to inspire and engage students and sharpen their leadership skills

- building a strong research agenda that supports the future of family medicine in an evidence-based way

- taking a leadership role in ensuring that new practice and consumer technologies are meaningful and serve patients' and practices' needs

Also speaking during the launch event was former CMS Administrator Don Berwick, MD, MPP. Berwick, who is the founding chief executive officer of the Institute for Healthcare Improvement, addressed the Triple Aim of the campaign - better health, better care, and lower costs_-and how Family Medicine for America's Health looks to foster the kind of primary care-based health care system that has been shown to realize these goals.

"There are only 2 possibilities of who is going to create this change," Berwick observed. "One is 'outside in' change. Those who are paying the health care bills and regulating the industry will use reward and punishment, change compensation systems and put in new metrics to correct the system.

"I don't think this is the preferred pathway. The better pathway - the elusive one-is 'inside out' change. Those who are in charge of the production of health care in America now have an opportunity to embrace this bigger set of goals-better care, better health, and lower costs."

Ultimately, said Berwick, "The best solution for America's achievement of reaching the Triple Aim is physician-led, patient-engaged, inside-out progress."

Finally, another participant at the launch event, noted author and filmmaker T.R. Reid, related a personal tale that clearly illustrated what's at the heart of the Health is Primary campaign: the patient-centered, holistic relationship between patient and physician that is the hallmark of family medicine.

A couple of years ago, he told attendees, he woke up and noticed one of his legs was a purplish color. Odd, but not life-threatening, it seemed. The next day, though, it was worse.

"I didn't know who to go to, so I went to my family physician," said Reid. "He looked at my purple leg for 5 seconds and said, 'You're fine. You're a snowboarder right? And we had a big powder dump on Tuesday. I bet you went up there and snowboarded and I bet you took a fall. You broke a blood vessel and that's why your leg is purple. It will heal itself, and in a week, you'll be fine."

The whole business cost Reid an $\$ 18$ copayment, he said, noting that had he gone to the hospital, it would have cost 7 times that.

The end result? "I got the treatment and diagnosis I needed from a primary care doctor," he said. News Staff AAFP News

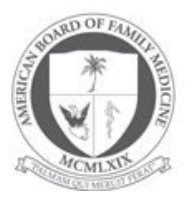

From the American

Board of Family Medicine

Ann Fam Med 2015;13:88-89. doi: 10.1370/afm.1745.

\section{ABFM'S SELF-ASSESSMENT MODULE (SAM) REVISION PROCESS}

In 2004, the first self-assessment modules (SAMs) went online as a resource for fulfilling the part II requirement of Maintenance of Certification for Family Physicians (MC-FP). As time has gone by, Diplomates have occasionally asked about the process the American Board of Family Medicine (ABFM) uses for revising and updating the content of the SAMs. Given the pace of change in medical knowledge, ABFM staff has found it necessary to employ multiple strategies to keep the SAMs current.

In an effort to obtain automated summaries of knowledge updates, our information specialist has worked with a physician to identify sets of search terms, called bedges, for use in the MedLINE/PubMed My NCBI tool available at the National Library of Medicine's PubMed website (http://www.ncbi.nlm. nih.gov/myncbi/). This site allows users to create and store literature search strategies that will run on a periodic basis to retrieve recent information on a given topic. These searches have been developed for every SAM item, and the staff reviews the results on a regular basis to identify significant new content or changes to existing information.

A second strategy is to have a member of the knowledge team that developed the SAM review the complete set of questions. Those that are no longer accurate or current are modified or replaced accordingly. In addition, some questions are removed to make room for new ones that reflect important developments.

Since Diplomates are permitted to repeat a SAM for MC-FP credits after 5 years have elapsed, a more 
in-depth review of the SAM is performed every 5 years by members of the original development team, as well as by new additions to the group, with a goal of replacing at least one-third of the questions.

Finally, the commenting feature accessible to Diplomates after completing the SAM questions has also proven to be a helpful tool for keeping SAMs up to date. As with the hedges, staff members review this feedback on a regular basis. In addition to providing input regarding ambiguous or controversial content, these comments can also alert our staff to content that has become outdated because of new recommendations or studies.

After a physician has revised or replaced a question, the changes go to the Content Development department. The new or revised content is then edited and incorporated into the department's database. From there, the new content is exported to the IT department, where it is moved into another database. The editors then review the questions once more in the format used on the Web., Cnce approved, the changes are deployed to our website.

While complex and labor-intensive, these strategies have served to keep the SAMs current and assure our Diplomates that the content remains dynamically responsive to the changing field of family medicine! Micbael D. Hagen, MD, Martin A Quan, MDi Roger Fain, MA, William DeBord, MSLS

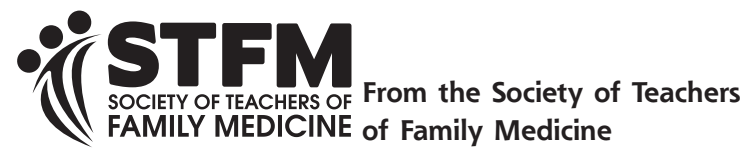

Ann Fam Med 2015;13:89-90. doi: 10.1370/afm.1749.

\section{STFM PREPARES FAMILY MEDICINE EDUCATORS TO LEAD}

There is a critical need for leadership development in family medicine. The Patient Protection and Affordable Care Act, the expansion of Medicaid in many states, and the aging population are driving the need for an expanded family medicine workforce. Medical schools and residency programs are jumping through hoops to educate a workforce to meet that need, in spite of the fact that health systems are incentivized to distribute Graduate Medical Education (GME) funding to subspecialty training. ${ }^{1-2}$

There is hope that the funding for both graduate medical education and primary care services may be changing. The nation is coming to realize that primary care must be at the foundation of a health care system that actually delivers better health, better health care, and lower costs. The July 2014 Institute of Medicine report, Graduate Medical Education That Meets the Nation's Health Needs, calls for changes to GME financing and governance to address deficiencies and shape the physician workforce for the future. Family medicine organizations introduced to Congress and the public new policy recommendations for graduate medical education. And Family Medicine for America's Health, a 20+ million dollar campaign launched in October 2014, is implementing strategies to ensure broad access to sustained, primary care relationships; reduce health care disparities; transform training; and facilitate a transition from fee-for-service payment to comprehensive payment. ${ }^{3-5}$

All of is happening as residency programs and fellowships are adjusting to changes in the graduate medical education accreditation process, including the transition to a single accreditation system.

Change such as this requires leadership from all of family medicine. Physicians, educators, researchers, and other health professionals need to be prepared to step up and advance change in programs, practices, institutions, and communities. "Leadership offers the enviable opportunity to influence the course of events: it direction, its content, and its texture," points out STFM President Sam Cullison, MD.

STFM is helping family medicine educators prepare to lead change and to lead in the midst of change. Two Leading Change task forces have been charged with developing and disseminating curriculum and resources to educate and empower family medicine faculty. The first launched a series of 12 free online modules. The second is working on:

- Curriculum for live presentations on topics such as Calibrating the Leader, Power and Politics of Change, Creative Leadership, and Building the Team. This curriculum will be tailored for established fellowships, conference/preconference workshops, and STFM On the Road presentations. The first training session will be at the 2015 STFM Annual Spring Conference.

- An indexed online toolkit that includes links to:

- References listed in the Leading Change online modules

- Worksheets, forms, and assessment tools to accompany the modules

- Recommended readings

- Case studies

- Previous fellowship projects

- A yearlong leading change fellowship that will offer mid- to senior-level faculty the opportunity to enhance their ability to lead change by applying the existing Leading Change curriculum to an actual change opportunity within their institutions 